\title{
Review of Lok Purusha Doctrine of Ayurveda Psychology in Cognitive Correction during Counseling
}

\author{
Thushara Joy
}

\begin{abstract}
Perceptual errors and cognitive distortion is considered as a main reason behind maladaptive behavior of individuals. In Ayurveda psychology cognitive correction utilizes principles of a doctrine termed as Lok purusha or the theorem of interconnectedness of man and universe. The doctrine has various components which are utilized for counseling especially while providing psychological first aid for a trauma affected patients and in grief counseling. The previous published works published are focused upon the physiological, anatomical and spiritual utility of this doctrine. On the other hand this theorem stands as a base for various cognitive therapies in Ayurveda. The publications regarding the utility in psychology are not to be found. Hence this review article is an attempt to bring light into the doctrine's multiple dimensions of sociology neurology and psychology and elaborate how it is applied in the cognitive therapy of Ayurveda.
\end{abstract}

Index Terms- Ayurveda psychology, Cognitive therapy, Counseling, Lok purusha, siddhanta

\section{INTRODUCTION}

The connection between man and the world around him, have been beautifully narrated in Ayurveda through the doctrine named 'Loka purusha siddhanta' [1].Here, man is considered as the epitome of universe. The understanding of this principle has been done in physiological, spiritual and anatomical levels, in the previous works. This theorem stands base for a few measures of Ayurveda, in management of errors in cognition. This work is an attempt to critically analyze the principle with the existing neurological, sociological and conventional psychological theories as a background.

\section{REVIEW}

\section{A. "Loka purusha siddhanta"-doctrine of Man and Universe relatedness}

The theorem of Loka purusha, conveys the idea that "Man is a Microcosm of the macrocosm-the Universe. $\mathrm{Al}$ that is present, or happens in the world around him, has its reflection upon him". This understanding has been further expanded into different levels of physiological functions and anatomical structure of the body. The spiritual understanding of this theorem is done by equating it with the philosophy of

Thushara Joy, Ayurveda Mental health practitioner, Thrissur, Ernakulam, Kerala, India
'Brahma anda' i.e. the greater consciousness gets reflected upon an individual as the living consciousness. Understanding of this theorem on a sociological, neurological and psychological perspective will be further detailed here.

\section{B. Sociological perspective.}

This theorem shows the connectedness of an individual to the society he belongs to. "All that happens around me has a possibility to replicate it in my life' [2] is a thought that arising out of it. This also suggests the reason for the oneness, people often feel, between each other in a society. The interconnectedness of humans have been depicted, even in the Vedanta philosophy as 'Ghada akasha.' [3] Ghada, means a pot and akasha, means sky. The sky which is infinite gets filled into the pot. The sky within the pot is one and the same, with the one outside, except for the fact that, it is separated by the boundaries of the clay of the pot. The changes that occur in the sky would certainly have a reflection, in the sky within the pot.

The concept of Collective Consciousness can also be explained, in the same perspective. The Collective Unconscious is a concept, originally defined by psychoanalyst, Carl Jung. It refers to the idea that, a segment of the deepest unconscious mind is genetically inherited and is not shaped by personal experience.[4] The phrase collective consciousness is taken here as the strong sense of a shared feeling of being together with others in a single or unified field of experience[5]. The connectedness of human beings explained through both these theorem is depicted in Fig1.0

\section{Neurological perspective}

Social awareness, reflective self-consciousness and inter subjectivity, have been explained with the discovery of mirror neurons. Mirror neurons, in the premotor and posterior parietal cortices of human brain respond to the intentions as well as the actions of other individuals in his society. There are also mirror neurons in the anterior insula and anterior cingulate cortices which respond to empathy[6]. Such mirroring abilities help to facilitate imitation behavior and empathy among individuals. The sense of oneness, felt by a group, is considered to have aroused out of this mirroring effect. [7]

Other than the brain based explanations quantum physics also give explanations involving various sorts of physical fields where separate events demonstrate significant relationships. Bohm's 'holographic' theory, Murphy's theory of an 
'interpersonal field', Roll's 'psifield 'theory, and Laszlo's 'cosmic plenum ' are a few theorems said to involve such interactions.[8]

The collective consciousness Represented as Akasha

The individual selfRepresented as Ghada

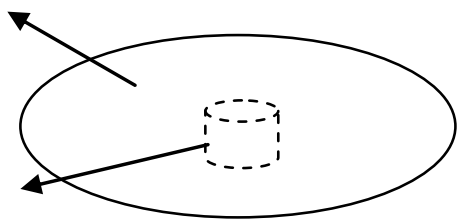

Fig1.0 Representing Ghada Akasha and collective consciousness

\section{Perspective of Ayurveda Psychology}

The Loka purusha siddhanta of Ayurveda acts as the principle for framing psychotherapy measures for cognitive correction in patients with grief and who have undergone a traumatic experience. The components of this theorem are:

1) Acceptance - Viyogaha lokaswabhaval

In conditions of loss or trauma the essential feature one needs to have is the resilience. The psychological resilience building begins from accepting the situation's reality. Denial is a defense mechanism developed by the mind to mitigate the grief arising out of loss. That mechanism would provide comfort for a short span of time. The reality acceptance has to be brought out gradually in an individual through various measures implemented with caution to cope up with a loss. To understand that, everything in nature has a time to perish and to accept, we are one among those transient beings, is the prime idea conveyed through Loka purusha theorem.

2) Feeling of oneness- Lokam athmani pashyathe The theorem brings in awareness that we are the part of a bigger picture. The social capital we have is the main base for an individual to recover from the phase of a disaster event. The support from the social circle and the feeling of being connected to others makes one feel secure. This principle is implemented effectively while providing Psychological first aid, during disaster management[9].

3) Internal locus of control-Atmeva karta

'The cause for happiness and grief in ones' life is their own action $_{1}$ '- is the secondary knowledge conveyed in Loka purusha theorem. Behavioral correction is possible in an individual, when he accepts the cause for their success or failure, is a result of his own action. This condition is called Internal locus of control.[10] On the other hand one who blames the world around him for his failure is considered to have an external locus of control.[11] Here the individual correction is envisaged through creating an internal locus of control

\section{4) Cognitive refinement-Satyabhudhi}

The purpose of this theorem has been detailed as cognitive correction or arousal of Satya budhi in an individual. 'The true knowledge is considered as the knowledge where one understands extreme attachment to the sensory objects and world outside, brings in subsequent grief when the object perishes of'.[1] Hence attachment with detachment or passive attachment is considered to be the mode to stay happy in this transient world. This concept is considered as the basis of grief counseling in Ayurveda. The components of cognitive correction used in Ayurveda psychology have been depicted in Fig2.0

\section{DISCUSSION}

Cognition is considered as a higher mental function of brain. The behavior of an individual is determined by the underlying cognitive process. In situations of trauma or disaster the errors in cognitive process leads a person into states of mental ill health. Sociability of a person and the cohesion he maintains with the world around him, becomes a major factor in grief recovery. This principle of Loka purusha siddhanta- doctrine of man and universe relatedness provides the key elements necessary for building up a social capital. The cognitive correction aimed is a state of detachment and expanded self-awareness. This further reduces the incidences of grief due to transient loses in life.

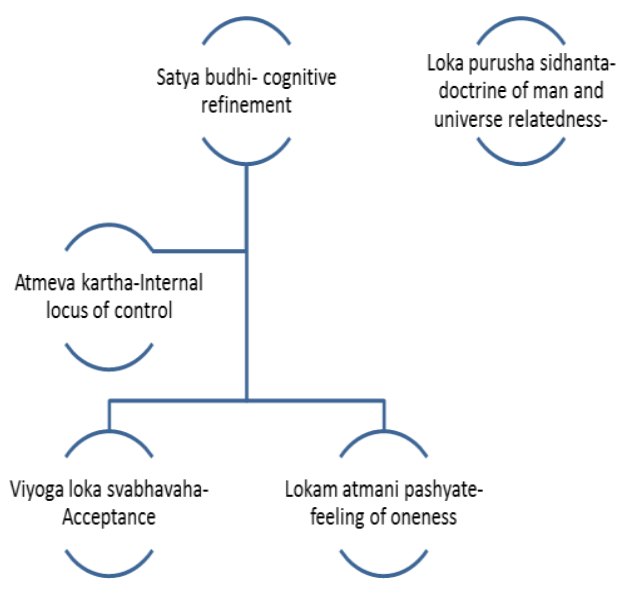

Fig2.0 Depiction of the cognitive correction process through Loka purusha siddhanta

\section{CONCLUSION}

The Loka purusha sidhanta-doctrine of man and universe relatedness establishes a theorem which has multi-dimensional explanations even in neurological and sociological planes. The application of the theorem, in grief and trauma counseling can improve the psychological resilience of an individual.

\section{REFERENCES}

[1] Charak Samhita, Sharirasthan - Purushavichayam shariram, 5/5, Shree Gulabkunverba Ayurvedic society, Jamnagar, Reprint, 2005; 3: 1072.

[2] "Lok purush samya sidhant" - a critical review. Jadhav et al. Wjpr8/7/2019

[3] Swami Gambirananda Mundakopanishad, Calcutta, Adwaita Ashramam 1986

[4] Jung, Collected Works vol. 8 (1960), "The Structure of the Psyche" (1927/1931), 317-320 (pp. 150-151).

[5] Filippini, Michelle. 2017. "Collective Organisms." Pp.44 in Using Gramsci. London: Pluto Press. URL: https://www.jstor.org/stable/j.ctt1h64kxd.9

[6] Borg, E. (2007), 'If mirror neurons are the answer, what was the question?', Journal of Consciousness Stud Baev, K.V. (1998),

[7] Biological Neural Networks: The Hierarchical Concept of Brain Function (Boston: Birkhäuser).ies, 14, pp. 5-1

[8] George, L. and Krippner, S. (1984), 'Mental imagery and psi phenomena: A review', in Advances in Parapsychological Research, Vol. 4, ed. S. Krippner (Jefferson, NC: McFarland), pp. 64-82. 
[9] Robert D. Putnam (7 August 2001). Bowling Alone: The Collapse and Revival of American Community. Simon and Schuster. p. 19. ISBN 978-0-7432-0304-3

[10] Carlson, N.R., et al. (2007). Psychology: The Science of Behaviour 4th Canadian ed.. Toronto, ON: Pearson Education Canada

[11] Rotter, Julian B (1966). "Generalized expectancies for internal versus external control of reinforcement". Psychological Monographs: General and Applied. 80 (1): 1-28. doi: $10.1037 / \mathrm{h0092976}$

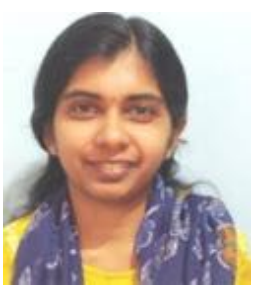

First Author Thushara Joy MD-Ayurveda mental health- Manovigyan Avum Manasroga from VPSV Ayurveda College Koottakkal, Kerala; BAMS from AMRITA School Of Ayurveda, Kollam,Kerala India,

Current position: Specialist Medical officer National AYUSH Mission Thrissur,Kerala, India ;

Main Paoers: Joy Thushara; CV Jayadevan. A critical analysis on the concept of pratidwanta cikitsa at par with PFA. Journal of Ayurveda and Integrated Medical Sciences (ISSN 2456-3110) http://www.jaims.in/index.php/jaims/pages/view/Citation, v. 3, n. 6, p. 139 - 143, jan. 2019.; A comparative study of symptoms of kirika in text Bhranthukalpam with similar references in traditional texts of Ayurveda IJCR 2020/01/30; 